\title{
جهود المعلم في ترقية مهارة الكلام للطلاب الجدد
}

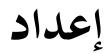 \\ 1 \\ نور عزيزة لوبيس \\ على أسرون لوبيس
}

\section{ملخص البحث}

من موضوع هذا البحث تصدر احدى المسائل هي كيف جهود المعلم في ترقية مهارة الكام للطلاب الجحدد في الجحامعة الإسلامية الحكومية بادانج سدمبوان،ماهي تحديات التي تواجهها المعلم في ترقية مهارة الكلام للطلاب الجلدد في الجحامعة الإسلامية الحكومية بادانج سيدمبوان، ماهي الحلول التي طبقتها في ترقية مهارة الكام للطلاب الجلدد في الجحامعة الإسلامية الحكومية بادانج سدمبوان.

بناء على تلك المسئلة، كان أهداف في هذ البحث لمعرفة جهود المعلم في ترقية مهارة الكلام للطلاب الجلدد، لمعرفة تحديات التي تواجهها المعلم في ترقية مهارة الكلام للطلاب الجدد في الجامعة الإسلامية الحكومية بادانج سيدمبوان، لمعرفة الحلول التي طبقتها في ترقية مهارة الكلام للطلاب الجلدد.

يتم هذ البحث في الجامعة الإسلامية الحكومية بادانج سيدمبوانيستخدم بمنهج لكتابة هذا البحث هيالكمية الوصفية البحث المتصور الظاهرة، ولجمع المعلومات يستخدم الألة هي مقابلة والملاحظة. 
بعد أن اقيمت الدراسةعن الترقية مهارة الكلام للطلاب الجدد، فجهود المعلم في

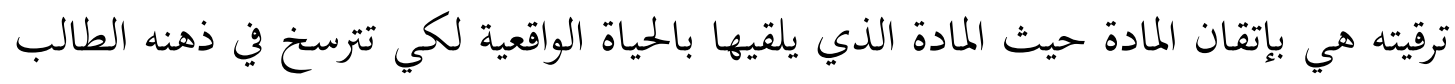

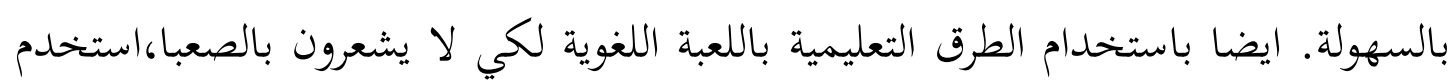

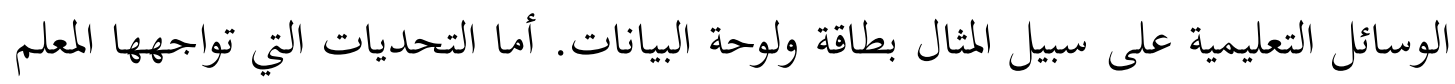

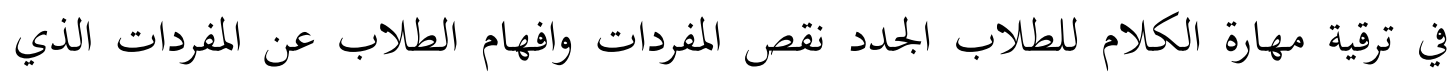

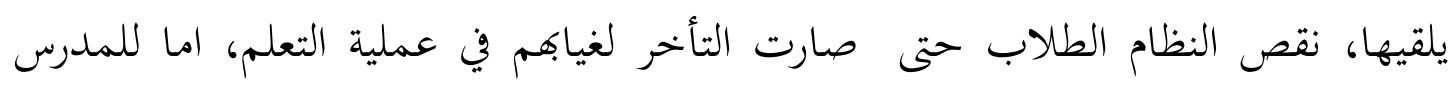

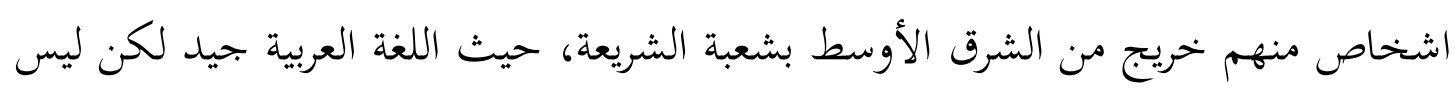

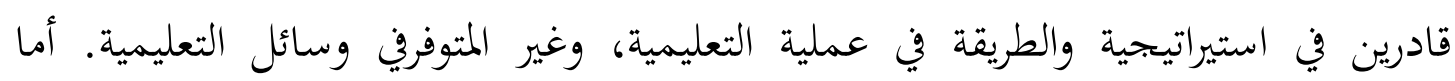

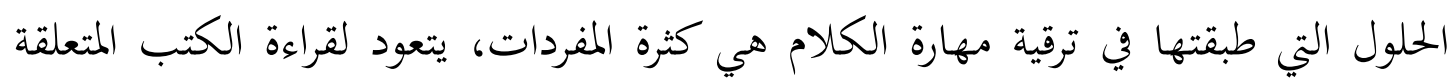
بالعربية والتحدث بالعربية بينهم.

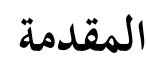

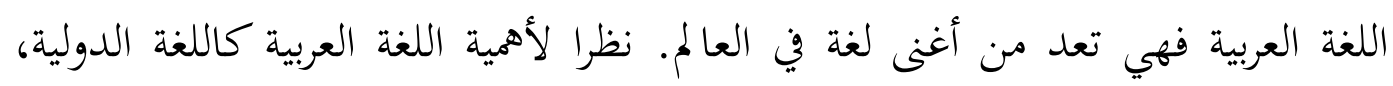
فظهر ارتفاع رغبة المتعلمين من بلاد شتى في تعلم اللغة العربية ولديهم أهدافهم المتنوعة.

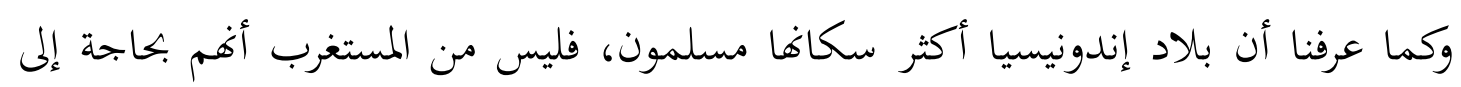

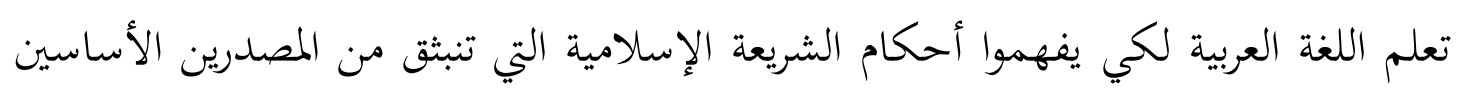
القرآن الكريم والحديث الشريف، وهما مكتوبان باللغة العربية.

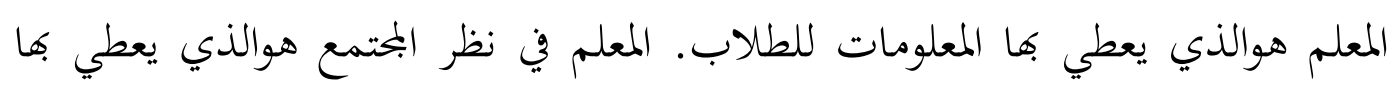

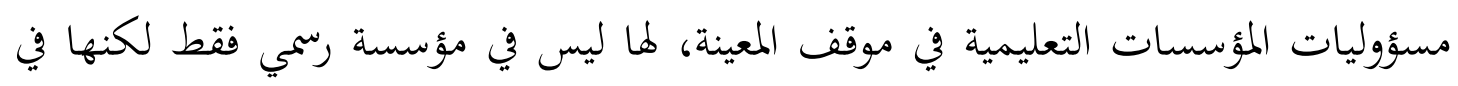

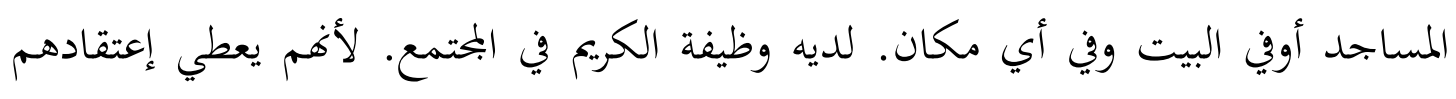


من المجتمع عن اطفالهم · لذا يعطي به المجتمع باعتقادهم، فالمعلم يعطي اليه الوظيفة والمسؤولية القوية .

على أساس خلفية البحث هذه المسألة أن الطلاب الذين يسكنون في المعهد الجامعة جامعة الإسلامية الحكومية بادانج سيدمبوان يلزم عليهم للتحدث باللغة العربية هم يشعرون بالصعبة في التحدث باللغة العربية لأن بعضهم قد خرجوا من مدرسة المختلفة، عدد من الطلاب خرجوا من مدرسة الثانوية الحكومية أوما عندهم مفردات الغني والأهم أن البيئة

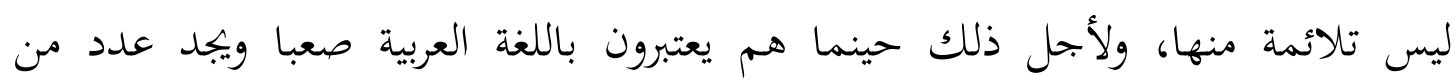
الطلاب خجولا .

اذن لمعرفة اى مدى بنحاح المعلم في إلقاء المواد في ترقية مهارة الكالام للطلاب، هتم

الباحثة هذه الرسالة بالموضوع" جهود المعلم في ترقية مهارة الكلام للطلاب الجدد ".

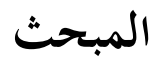

أ- مفهوم الجهـد

الجهود هوالجها، شرط لمتطلبات الشئء، جهد، يسعى لتحقيق الشئ المطلوب. لتنال الغرض وتحليل المشكلات المراد هنا يعني بذل الجههد، دور والعملية الذي يعمل لخصول المقصود الكاملة في ترقية مهارة الكام. 1

ب- - مفهوم المعلم المعلم في معجم الكبير الإندونيسية، هم لديهم المهنة أويدرسون.

${ }^{1}$ DwiAdi K, KamusPraktisBahasa Indonesia( Surabaya: FajarMulya, 2001), hlm.576 
لاشك أن المعلم حجر الزواية، في عملية التطور المنشود، لأن المسؤول عن تنشئة الجيل الجحيد، وهوالذي يمده بالوسائل التي تعينه على تفهم الحياة، ويمكنه من التشبيع بالأهداف العامة التي ينشدها البحتمع لنفسه ولإفراده.

والمعلم رائد طلابه وطالباته، وقدوة حسنة لهم، وهوبقوة شخصيته وتكاملها، وقدرة على التوجيه، وحسن تصرفه في المواقف المختلفة وفهمه لمشكلات طلبته أوطالباته، وحبه لهم، وحرصه على النظام واحترامه له، واتزانه الإنفعالي انه لكل ذلك وته يستطيع أن يكون قدوة خيرة لهم.

المدرس ليس فقط ايصال المعلومات للطلاب لكنه المتخصص الذي يصبحهم قادرين للتخطيط، للتحليل وإتمام المشكات الذي يواجهها. بذلك ينبغي أن يكون المعلم همة العالية، تربية الواسعة، شخصية القوية مع الانساني الذي يعميقه. ت - دور المعلم

دور المعلم مهم في عملية التعليمية، التي تنفذ أنشطة في فصول الدراسية، وانه من الآن نموذجا للطلاب وتشجيعهم على تصحيح الأخطأ الى الإعتماد أنفسهم، المعلم هوالذي يدير العمل، وتمكنت من ضبط النفس ولكن مع النشاط. كما قال همزة في كتابه اى هناك العديد من أدوار المعلمين في التعلم: ب- ألمعلم كمصمم التعليمي( مصمهم للتعلم)

${ }^{2}$ PusatBahasaDepartemenPendidikanNasional,KamusBesarBahasa Indonesia ( Jakarta: KaryaAbditama, 2001), hlm.578

${ }^{3}$ H. Syafruddin, ,dkk. Guru Profesional Dan ImplementasiKurikulum(Jakarta: CiputatPers: 2002), hlm.7-8. 


$$
\begin{aligned}
& \text { ت- المعلم كمرشدين التعلم } \\
& \text { ث- المدرسين والمقيمين } \\
& \text { ج-المعلم كمستشار } \\
& \text { ح-المعلم كمامنفذي المناهج الدراسية } \\
& \text { خ-المعلم في المناهج القائمة على بيئة التعلم } \\
& \text { د- واجبات ومسؤوليات المعلمين } \\
& \text { ذ- شروط المعلم الجيد والناجح } 4 \\
& \text { ث- صفات المعلم اللغة العربية } \\
& \text { أولا: الصفات العامة للمعلم } \\
& \text { أ- الصفات العقائدية }
\end{aligned}
$$

نعنى بها الإيمان الراسخ للمعلم، أى معتقده الذي يؤمن به. ومن هنا تمكن خطورة المعلم في غرس المعتقدات والقيم التي يود صانع السياسة التربوية أن يغرسها في أبناء الوطن وناشته، فسلوكيات المعلم هي التي توجه الأجيال وبتعلها تتشكل وفقا لما، فالمعلم قدوة بجانب كونه متخصصا في مادة معينة، ولذك فإن سلوكياته هي التي يقتدى بها تلاميذ هويعملون بقصد أوبدونه على تقليدها. فالمعلم المسلم لابد أن يؤمن إيمانا راسخا بالعقيدة الإسلامية، بكيث توجه هذه العقيدة أفكاره وتصرفاته، وبتعله يقوم بهمامه في ضوء تلك العقيدة من جهة،

$$
\begin{aligned}
& \text { ويعمل على تشرب التلاميذ لما من جهة أخرى. } \\
& \text { ب- - الصفات الجسمية }
\end{aligned}
$$

${ }^{4}$ Hamzah B Uno, ProfesiKependidikan ( Jakarta: BumiAksara, 2011), hlm.22 
1. ينبغي أن يتمتع المعلم بصفة عامة بصحة جيدة، فخلوجسمه من الأمراض

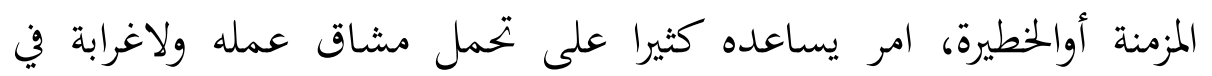
ذلك، فالتدريس مهنة شاقة تتطلب جهدا فكريا بالإضافة الى جهد البدني.

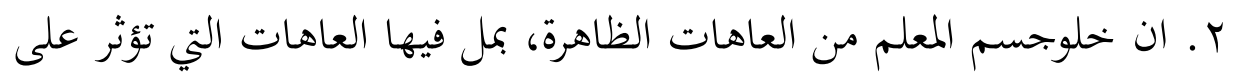
حالاته الصحية العامة. ومن أمثلة ذلك عيوب اللسان والفم، التي تئثر في

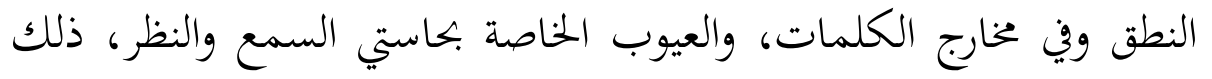
ان مهنة التدريس تعتمد على التفاعل اللفظي بين المعلم والتلاميذ، وهوما

$$
\text { م. بتطلب سلامة هذا الحواس. }
$$

1. ينبغي أن يتمتع المعلم بمعرفة واسعة وعميقة في بحال المادة الراسية التي يقوم

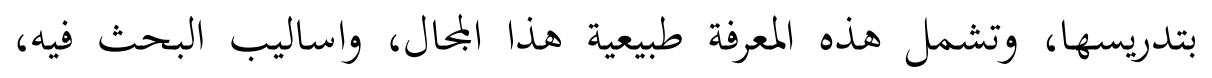

$$
\text { وقدر من المعلومات الرئسية في فروعه المختلفة. }
$$

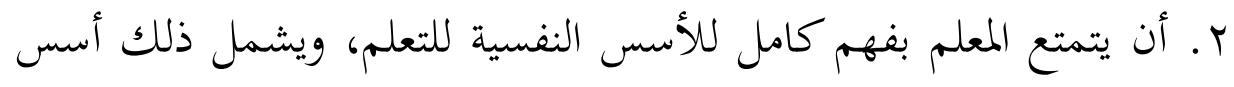

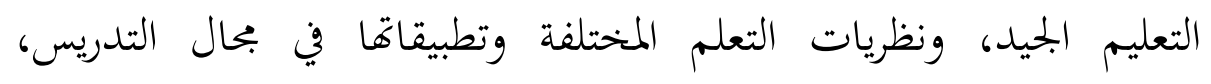

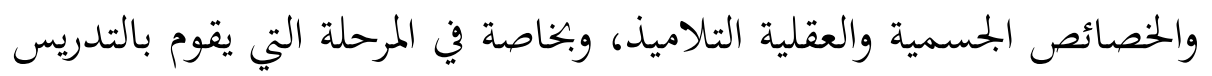
فيها.

ثانيا: الصفات الخاصة بمعلم اللغة العربية

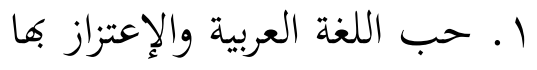


لعل من أميز الصفات التي يتعين على معلم اللغة العربية أن يتصف بها،

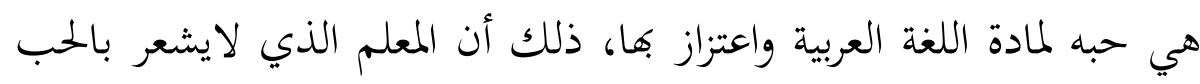
للمادة التي يقوم بتدريسها، لايستطيع أن ينقل هذا الحة الحب الى الى تلاميذه. r. إن التكمن من اللغة العربية

هذه الصفة ضرورية ولازمة لكل معلم كما ذكرنا إلا أن معلم اللغة العربية لايستطيع تحقيق مهمته، ولاالسير بدرسه خطوة واحدة اذا لم يكن فيكن متمكنا من مادته، غنى الثروة الأدبية والزاد اللغوي. r. التمام العربية تحدثا وكتابة

هذا يتطلب من المعلم أن يكون نموذجيا حيا في نطقه وكتابته، فالنطق الجيد

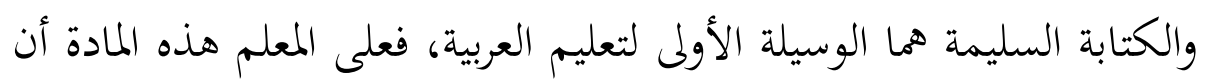

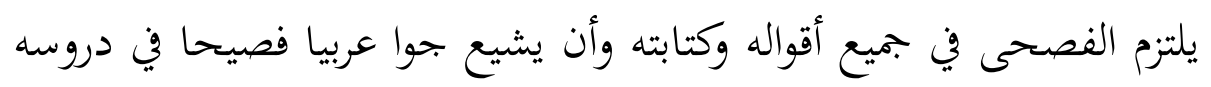

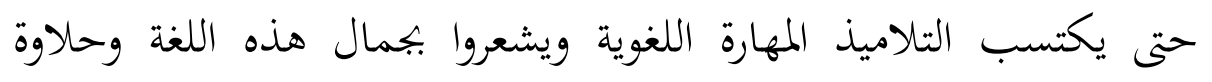
جرسها وإيقاعها.

$$
\text { ع ـ القدرة على الإبداع الأدبي }
$$

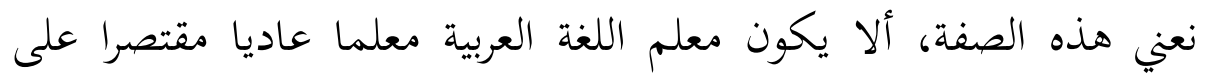

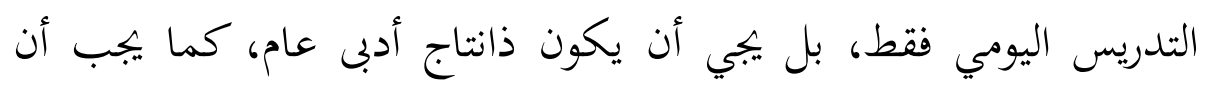

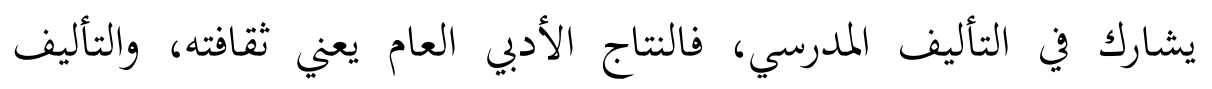

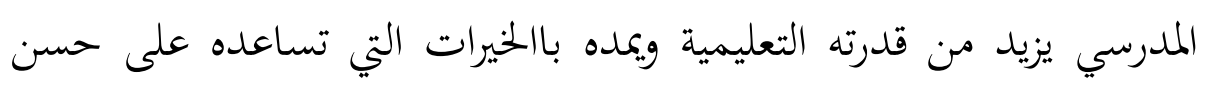
القيام بكمته التدريسية، ولاسيما بالأنشطة اللغوية غير الصفية. 


$$
\text { ج - واجبات المعلم }
$$

كما قال أوزير عثمان ان المعلم لديه العديد من الواجبات، كلاهما من واجب اوخارج

الخدمة، عندما كنا تنظيم هناك ثلاثة أنواع من واجبات المعلمين اى في بحالات

$$
\text { المهنية من الإنسانية وفي بحالات المتمع. }
$$

واجبات المعلم كمهنية على محتوى تدريب، تعليم، ممارسة. تعليم هومواصلة وتطوير

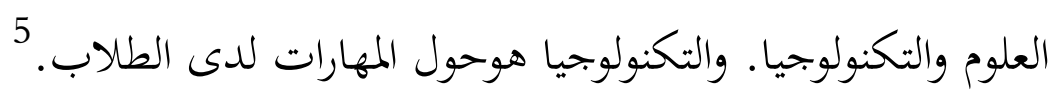

لكي يؤدي المعلم واجباته على الوجه الصحيح عليه أن يتبع الإرشادات الآتية:

1. أن ينظر الى طالبته كأفراده في بحموعة فلا ينظر اليهم كوحدة أوبحموعة، حتى

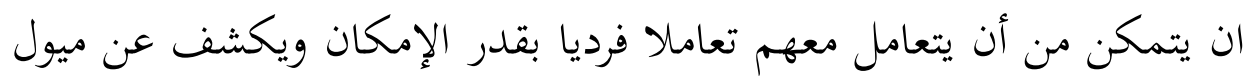

ورغبات كل منهم في كل فرصة الى معرفة البيئة التي تعيش فيها، من النواحي

الإجتماعية، والإقتصادية والثقافة حتى يتسنى له بذلك معاملة الطالب اوالطالبة

وتوجيهه بما يتفق والحالة التي هي عليها.

r. أن تقوم العلاقة بين المعلم وطلبته أوطالباته على أساس الإحترام المتبادل.

r. أن يوزع انتباهه وعطفه ورعايته على جميع طلبته أوطالباته لسد حاجتهم

الوجدانية التي يفتقدوها بانتقاهم من بيئة البيت الى بيئة المدرسة الأوسع المعانه

$$
\text { والأكبر عودا. }
$$

hlm.4-5

${ }^{5}$ MohUzerUsman, Menjadi Guru Profesional,( Bandung: PT Remaja Rosyadakarya,2011) 
ع. أن يقدر فردية كل واحدة من طلبه وطالباته، ويتعرف بما لديها من خصائص تمييزهاغيرها، فيراعى شعورها ويستمع لها ويتيح لها الفرص كي تنمونموا متزنا وكي تنكشف قدراها ونزعاتا.

\section{ح-كفاءة معلم اللغة العربية}

قال محمود اسماعيل الصيني إن الصفات المنشودة في معلم اللغة العربية هي صفات ذاتية وتأهيلية، ومن الصفات الذاتية فهي قناعة بأهمية اللغة العربية ودورها الخطيرة

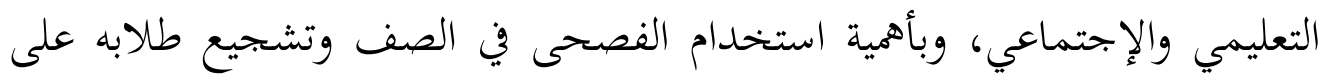

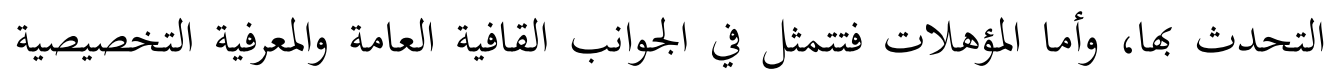
والتربوية، الى جانب الكفاءة في اللغة العربية.

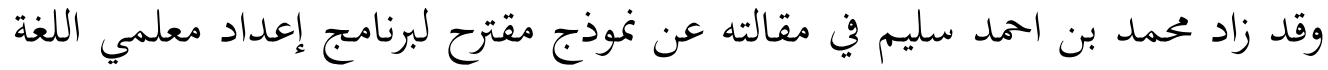
العربية لغير الناطقين بها إن اهم كفاءة التي لابد عند المعلم اللغة العربية هي:

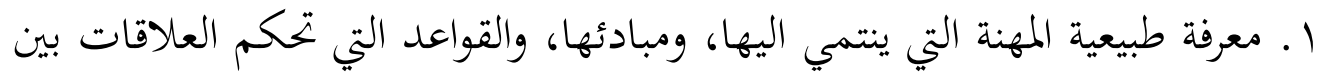
أعضائها. r. القدرة على المشاركة في تخطيط وتنفيذ برامج تعلم اللغة العربية لغير الناطقين .

r. معرفة الطرق والأسالب الفعالية في تعليم اللغة العربية لغير الناطقين بها . ع. القدرة على تعليم المهارات اللغوية بمفاهيم الثقافة العرية الإسلامية.

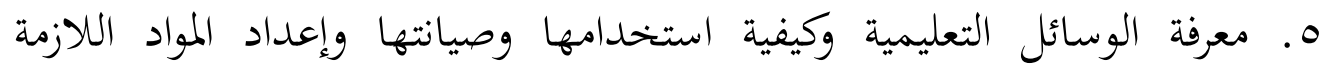
وتدريب الطلاب على استخدامها.

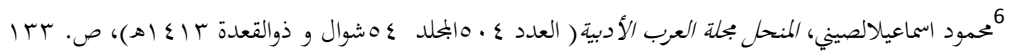


ج. القدرة على المشاركة في تقويم وتطوير برامج تعليم اللغة العربية لغير الناطقين بها. V. القدرة على بناء الإختبارات بأنواعها المختلفة.

م. معرفة أساليب النقد الذاتي التي تساعد المدرس على الاستمرار في تحسين مهارته التدريسية داخل الفصل الدراسي.

9. القدرة على إجراء بحوث محدودة في بحال تعليم اللغة العربية لغير الناطقين بها بهدف التعريف على المشكلات الدراسية وعلاجها وتطوير العملية التدريسية. • ا. معرفة فروق الفردية، الشخصية والثقافية للمتعلمين، ومراعاة ذلك في عملية

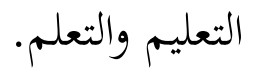
خ-مفهوم اللغة

كما قال شيف المصطفى اى اللغة هي ادوات التواصل التي تستخدم لتتفاعل مع بعضها البعض وتستخدم الأفكار الموجودة في العقل يعبر عنه بشكل أفضل من خلال الكلام والكتابة. 7

ويمكن الحصول على المهارات اللغوية التي كتبتها تعويدا. في حد ذاته شكل من أشكال التنفيذ هوممارسة مرارا وتكرارا في برنامج مدرجة في تكرار طريقة العناصر مع ممارسة مثلا. اتم الحصول على مهارة الاستماع . يمكن ان مهارات الاستماع تعرف عليها عن طريق نموذج تقرير افصاح ما يفهم من الحديث. ومن اهل المهنة من المستحيل أن يتكل دون الاستماع من قبل، حتى الحمديث عن ما استمع المهارات اللازمة لإظهار مهارةم في الاستماع، لذلك هوبسبب اللغة المنطوقة واللغووالسائل ماهرا التحدث والاصغاء، اوالعكس نسمع المهارة بالعكس، وتتحدث. hlm.136.

${ }^{7}$ SyaifulMustofa, StrategiPembelajaranBahasaArabInovatif( Malang : UIN Maliki Press, 2011), 
د- مهارة الكلام

كما قال شبف المصطفى تعريف مهارة الكالام هي مهارة لنقل الرسالة لفظيا الذي يتأثر العوامل التي عمليا يمكن ان نرى، هوالنطق، التنغيم، اختيار الكلمة، تركيب الجمل، وخطوات المحادثة. 8

مهارة الكلام وغالبا تسمى التعبير كلاهما خلافات في التركيز. التي مزيد من التركيز على القدرة اللفظية ويمكن ايضا أن يتحقق في شكل من أشكال الكتابة. محادثة هي إحدى مهارات اللغوية الأربع بعد مهارة الإستماع، ترجمة اللسان عن ما تعلمه الإنسان من خحلال الاستماع القراءة والكتابة، لأن الكالام هوكلمة التي تحدث . يتحدث باللغة للتحدث عن أفكاره من العقل، على سبيل المثال هوالكلام واللغة، كما يدل على لك ما هوالمقصود من ركلة جزاء هونطق اصوات اللغة العربية بشكل صحيح وبشكل صحيح وفقا للأصوات التي تأتي مع المخرج معروفة من قبل اللغويات. هناك بعض اللغات مازالت منطوقة غير مكتوبة. ذ- مبحالات مهارة الكلام

1. التمييز عند النطق، بين الأصوات المتشابهة تمييزا واضحا مثل: ذ، ز، ظ الخ. r. اختيار التعبيرات المناسبة للمواقف المختلفة. r. استخدام النظام الصحيح لتراكيب العربية عند الكلام. ع. التحدث بشكل متصل، ومترابط مما ينبئ عن ثقة بالنفس وقدرة على مواجهة

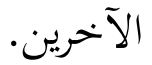
ه. إلقاء خطبة قصيرة مكتملة العناصر. ج. إدارة حوار هاتفي مع أحد الناطقين بالعربية. 9

${ }^{8}$ Ibid.,hlm. 137 
ر- أهداف تعليم مهارة الكلام

كما قال عبد الوهاب الرشيدي مع مملوعات النعمة اى أهداف تعليم مهارة الكلام

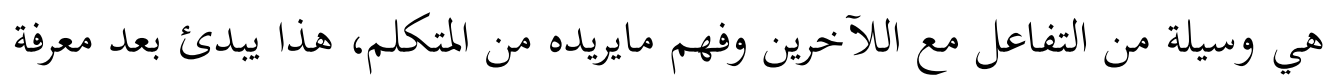
الطلاب أصوات العربية. 10

هناك أهداف عامة لتدريس الكلام يمكن أن تعرض لأهمها فيما يلي:

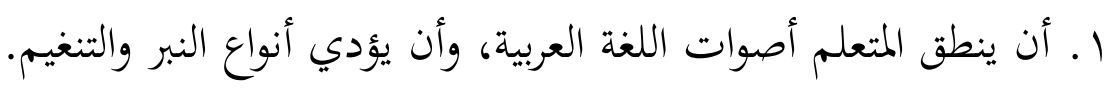
r. أن يدرق الفرق بين الحركات القصيرة والحركات الطويلة. r. أن أن ينطق الأصوات المتجاورة والمتشابهة. ع. أن يعبر عن أفكاره مستخدما الصيغ النحوية المناسبة.

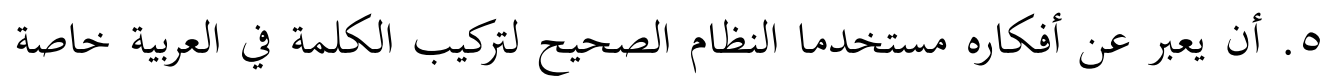

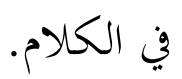

7. أن يستخدم بعض خصائص اللغة العربية في التعبير الشفوي والتأنيث وتمييز الحد والحال ونظام الفعل وغير ذلك.

V. أن يستخدم بعض أشكال الثقافة العربية المقبولة ومناسبة لعمره ومستواء

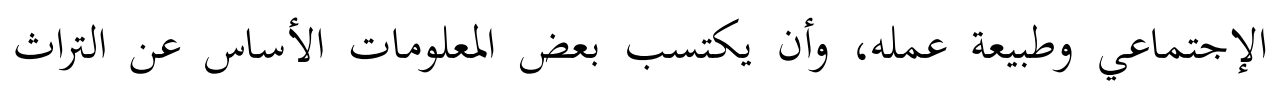
العربي الإسلامي. 1. أن يخز عن نفسه تحييزا واضعا ومفهوما في مواقف الحديث البسيطة.

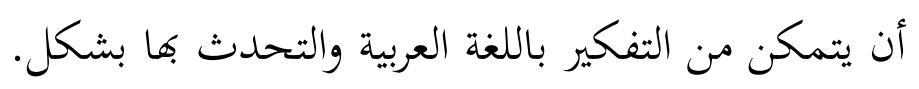

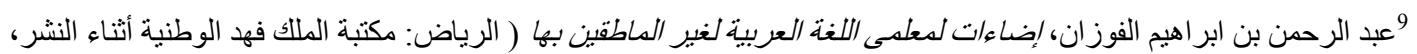

${ }^{10}$ Abd.WahabRasyidi, Mamlu'atulNi'mah,MemahamiKonsepDasarPembelajaranBahasa Arab( Malang: UIN Maliki Press, 2012), hlm.89. 
ز- زأهية مهارة الكلام

مهارة التحدث هي أهم مهارات في حديث جزء من المهارات المكتسبة من خلال

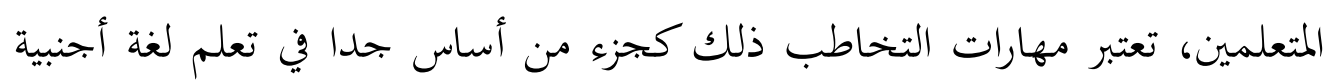
في سياق حديثه عن أهمية تعلم المهارات الختوى والمعنى في ايصال الرسالة لفظيا،

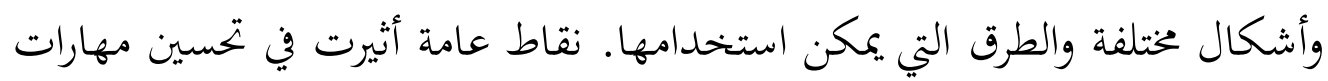
التحدث:

ا.تزويد الأطفال بثروة لغوية من الألفاظ والتراكيب التي تعينهم على التعبير عما

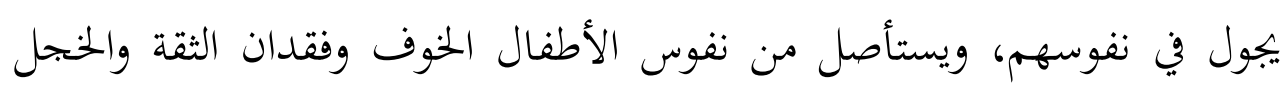

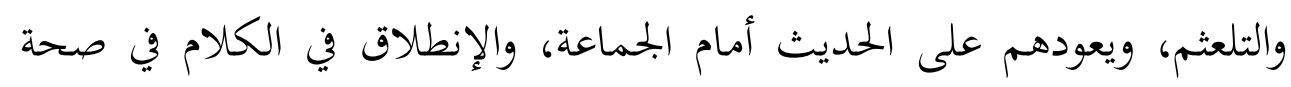

ووضوح.

r. يعودهم على طلاقة اللسان، وإجادة النطق وحسن الأداء.

r. بتيح الفرصة للمعلم أن يكتشف عيوب الأطفال النفسية واللغوية.

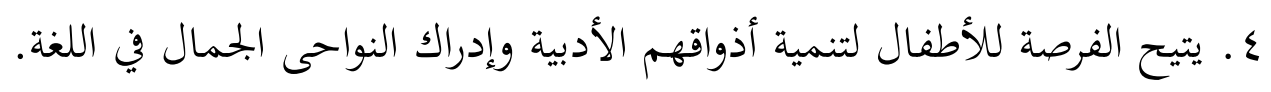

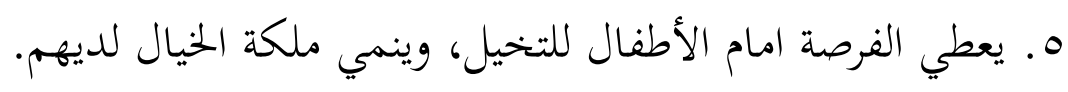

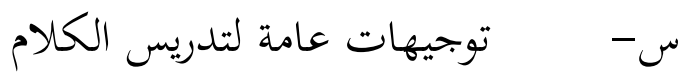

كما قال عبد الوهاب رشيدي مع مملوعات النعمة أن توجيهات عامة لتدريس لكارم

$$
\begin{aligned}
& \text { الكلام اي: }
\end{aligned}
$$

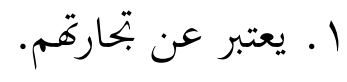

$$
\begin{aligned}
& \text { r r r التدرجي. } \\
& \text { r. ثيمات المتعلقة اشياء ذات قيمة في حياقم. } \\
& \text { ع . إعطاء تعليمات واضحة ومحددة. }
\end{aligned}
$$


ه. تدريب الطالب على التركيز.

7. حوافز عالية ورغبة القوية في الكلام. 11 ش - مبادئ عامة لتدريس الكلام

كما قال عبد الوهاب رشيدي مع مملوعات النعمة اى أن مبادئ عامة لتدريس

$$
\text { الكالام ایى: }
$$

$$
\text { ا ـ قدرة عالية من هذه المهارات. }
$$

r . بدا من اصوات مماثلة بين اللغتين ( متعلمى اللغة العربية).

$$
\text { ع. ع. بدا من مفردات البسيطة. }
$$

ه. تختار موضوعات للكالام من اهتمام الطلاب، يجب ان الكاتب والاهتمام المعلم الى مراحل في تدريس علم الكلام، مثل بدا الألفاظ سهلة تتكون من جملة

$$
\text { واحدة، جملتين وهلم جرا ومما يرغبون الحدث حولها. }
$$

T. تختار موضوعات حية واقعية مثل نشرات الأخبار والتقارير الصحافية والتعليق

$$
\text { عليها. }
$$

V . يشجع الطلاب على الحديث والطلاقة بلا خوف ولاخجل. 12 ص.مشاكل في أنشطة المهارة الكلام

${ }^{11}$ Ibid.,hlm. 93- 94.

${ }^{12}$ Ibid.,hlm. 93-94. 
كما قال عبد الوهاب رشيدي مع مملوعات النعمة اى ان مشاكل في انشطة المهارة

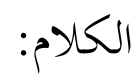

$$
\begin{aligned}
& \text { ا ـ يخطر الخطأ به. } \\
& \text { r. خوف انتقد به. } \\
& \text { r. لا فيها المواد ستناقش منها. } \\
& \text { ع. لا يمكن التفكير في ما سيقول. } 13 \\
& \text { وايضا كما قال عبد الرحمن بن ابراهيم الفوزان: } \\
& \text { 1. تهيب الطلاب من الكلام. }
\end{aligned}
$$

r. قد لايجدون ما يقولونه فالموقف ينسيهم ما يقولونه.

r. ضعف المشاركة في الحديث اوالحدمات.

ـ. استخدام اللغة الأم ولاسيما في الفصل الذي ينتمي طلابه المى خلفيه لغوية

$$
\text { واحده. }
$$

ص - الخطوات في عملية تعليم مهارة الكلام

كما قال عبد الوهاب رشيدي مع مملوعات النعمة اى أن هناك العديد من الخطوات التي يمكن استخدامها من قبل المعلمين عندماتشمل تعليم مهارات التحدث: ا ـ بالنسبة للمتعلمين المبتدئين

أ. بدا تدريب المعلمين في الحديث عن طريق إعطاء الأسئلة التي يجب الإجابة عليها من

$$
\text { قبل الطلاب. }
$$

ب.في الوقت نفسه يطلب من الطالب لتعلم نطق الكلمات، ويكون الجمل والتعبير عن

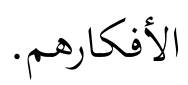

\footnotetext{
${ }^{13}$ Ibid.,hlm. 91-92.
} 
ت. يرتب المعلم الأسئة التي طرحت تمت الإجابة من قبل الطلاب حتى يتسنى للطلاب في

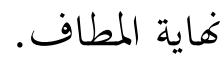
ث. يسأل المعلم الطلاب على الإجابة على تمارين الشفوية، حفظ المحادثات اويجب على اسئلة تتعلق بمحتوى النص الذي يحتوى يقرأ الطلاب.

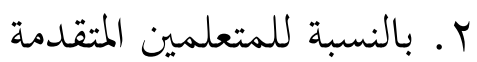

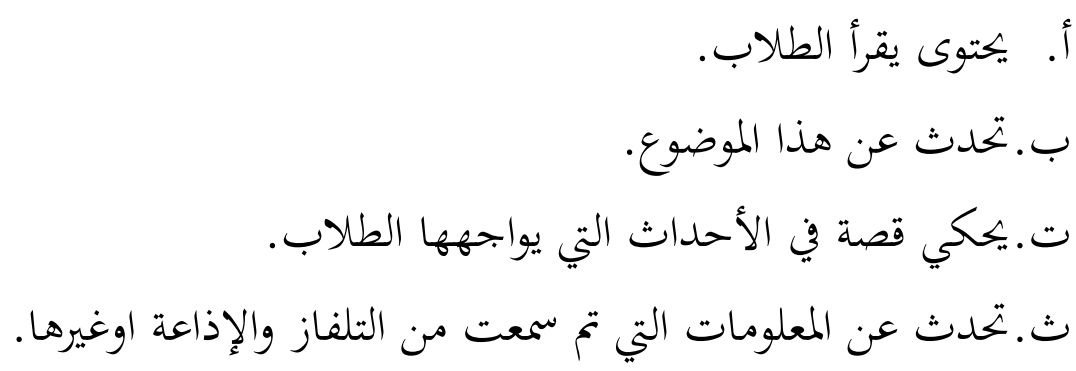
r. - م. بالنسبة للمتعلمين المتقدمة أ. يختار المعلم موضوع لممارسة الكلام. ب. موضوع المختار يجب ان تكون مثيرة للإهتمام الذي يتعلق بحياة الطلاب. ت. بيب ان يكون موضوع واضح ومحدود. 14 الخحلاصة

بناء على البحوث الذي يفعل عن جهود المدرس في ترقية مهارة الكلام في اللغة العربية في جامعة الإسلامية الحكومية بادانج سدمبوان هي: لإنيا: 1. جهود المعلم في ترقية مهارة الكلام للطلاب الجلدد في جامعة الإسلامية الحكومية

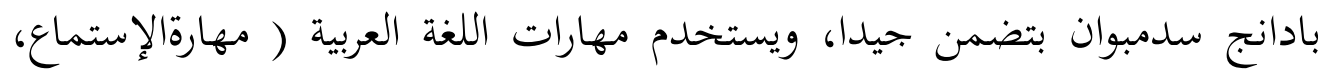

${ }^{14}$ Ibid.,hlm. 93-94. 
مهارة الكلام، مهارة القراءة، ومهارة الكتابة) إذاً يسعى المدرس اعطاء الشرح لفهم

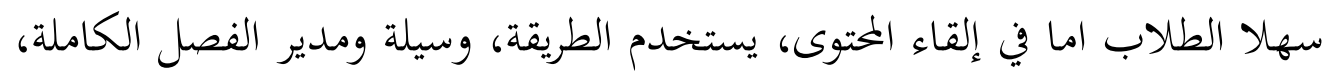

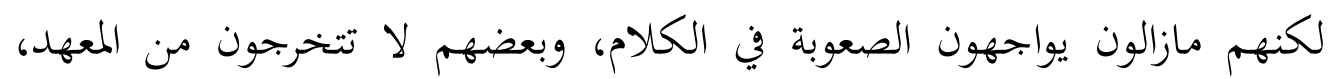

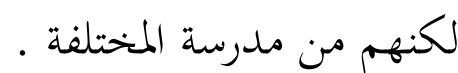
r. تحديات التي تواجهها المعلم في ترقية مهارة الكلام للطلاب الجدد في جامعة لماندان الإسلامية الحكومية بادانج سيدمبوان نقص المفردات وافهام الطلاب على المفردات

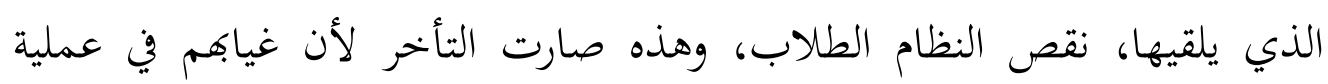

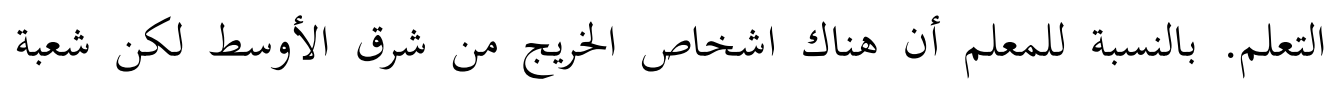
الشريعة، حيث اللغة العربية جيد لكن ليس قادرين استيراتيجية وطريقة في عملية التعلم.وتحديات الأخير هوغير متوفر الوسائل التعلم .

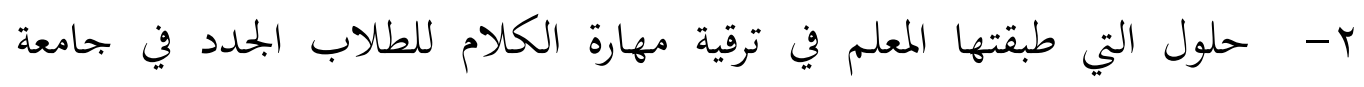

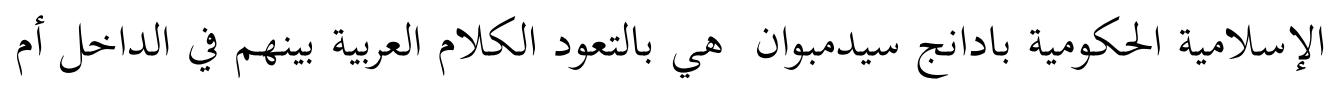

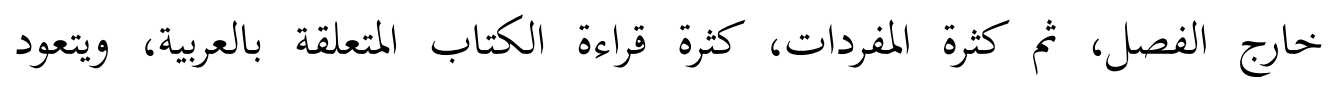
الإستماع الموسيقي العربية، بالتعود سيسهل الطلاب في الكلام العربية، والمعلم

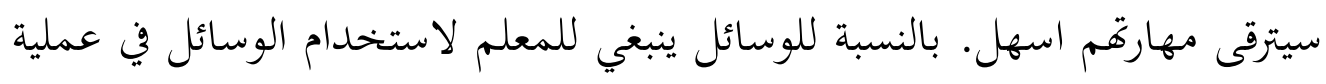

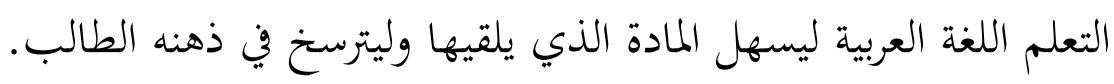




\section{المصادر والمراجع}

عبد الرحمن بن ابراهيم الفوزان، إضاءات لمعلمى اللغة العربية لغير الماطقين ها ( الرياض:

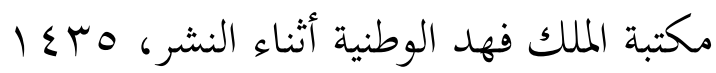

محمود اسماعيلالصيني، المنحل مجلة العبب الأدبية( العدد ع . هالمحلد ع ـشوال وذوالقعدة $1 \leqslant 1 \%$

Abd.WahabRasyidi, Mamlu'atulNi'mah,MemahamiKonsepDasarPembelajaran

Bahasa Arab, Malang: UIN Maliki Press, 2012

DwiAdi K, KamusPraktisBahasa IndonesiaSurabaya: FajarMulya, 2001

H. Syafruddin, ,dkk. Guru Profesional Dan ImplementasiKurikulum, Jakarta: Ciputat Pers: 2002

Hamzah B Uno, ProfesiKependidikan, Jakarta: BumiAksara, 2011 hlm.22

MohUzerUsman, Menjadi Guru Profesional, Bandung: PT Remaja Rosyadakarya,2011

PusatBahasaDepartemenPendidikanNasional,KamusBesarBahasa Indonesia, Jakarta: KaryaAbditama, 2001

SyaifulMustofa, StrategiPembelajaranBahasaArabInovatif, Malang : UIN Maliki Press, 2011 